\section{VHN 14}

RADIATIDN THERAPY AND TREATMENT RESULTS OF MALI GNANT TUMORS OF THE LOHER JAH!

H.D. Böttcher, U. Uagner, L. Schertel

Ue report about a retrospective study of a patient collective from the files of the Radiological Clinic of Münster University between 1.1 .1960 and $30,6.1983$. There thexe 79 cases of primary malignant tumors of the lower jat in 50 male and 29 female patients. More than $60 \%$ of these patients were 60 years and older when treatment started. 63 of the tumors mere histologically classified as carcinomas, and 16 as sarcomas.

of 60 patients treated with combined surgical and radiotherapy, 56 received postaperative, 2 pre- and postoperative, and 2 pre-operative irradiation. 19 patients were subjected to radiotherapy alone, mostly for palliative purposes.

Recurrencies developed in 14 of our 79 patients, 6 of them after surgical therapy alone.

The 3-year-survival among our 79 patients was

$48.8 \%$, the 5 -year-survival $44.6 \%$

The tumars were treated with paraliel opposed

fields in split course technique, with a focal dose of 50 Gy. A side effect of radiotherapy was radiation mucositis in two cases, there "uas no evidence of osteoradionecrosis.

of our 79 patients, 15 received additional chemotherapy for palliative, 3 for curative purposes.

Radiolagische Klinik und Poliklinik der Universität Münster.

Albert-Schteitzer-Strabe 33, D-4400 Münster

\section{VHN 15}

RADIATION THERAPY AND TREATMENT RESULTS IN MALIGNANT TUMORS OF THE TONGUE.

H.D. Bättcher, H. Hagner, L. Schertel

We report abaut a retrospective study covering patient material recorded in the Radiological Clinic of Münster University between l.1.1960 and 31.12 .1983 . During that period there were 164 tumors of the tongue in 114 male and 50 female patients ofith a mean age of 61 .years. Most of the tumors mere histologically classified as squamous epithelial carcinomas (92\%). The patients received the follawing therapies: 59 cases palliative radiotherapy alone, 19 cases radiotherapy with additional surgical and/or chemotherapy, 86 cases combined surgical and radiotherapy.

Recurrencies developed in $27 \%$ of all patients, the mean survival was 2 . I years.

Tumors of the tongue were treated with parallel opposing fields in split course techniques with a focal dose of 50 Gy. The side effects of irradiation were osteoradionecrosis in two cases (receiving total focal doses up to 92 Gy for recurrencies) and mucositis in 9 cases. The five-year-survival rate among these 164 patients was $22 \%$ with a slight difference between tumors of the glottal body ( 20 \% of the glottal fundus ( $25 \%)$. The overall prognosis of glottal tumors is stage-dependent.

Radiologische Klinik und Poliklinik der Universität Münster

Albert-Schweitzer-Straße 33, D-4400 Münster

\section{VHN 16}

RADIATION! THERAPY AND TREATRENT RESULTS OF MALIGNANT TUHORS OF THE NASAL CAVE

B. Glaser, L. Schertel, H.D. Bättcher and "iv. "legner

We report on retrospectively anelysed records of 43 petients ( 25 male and 18 fenale, aged $37-81$ years, mean 56) wi.th malignant tumors of the nesal cave, treated at the Radiologic Department of the University of liünster from 1961 untiI 1985.

The lateral nasel wall was primary site of the tumor in $29 \%$ of the patients, the septum nasi in $11 \%$ In $46 \%$ of the patients the primery site was not exactly defined. II \% of the tumors were carcinomas and $23 \%$ mere sarcomes.

Treatment : 11 petients received radiationtherapy only (with palliative eim), 26 had combined treatment with surgery and radiotherapy and 6 patients received additional chemotherapy in combination with surgery and radiotherapy. Radiation therapy was done under supervaltage conditions with 2 - or 3-field techniguss. The reference dose due to the target volume was 50 Gy. If lymphatic nodes were involved the target volume was extended to the aree of the primery tumar site and the lymph node ereas of the neck. 30 of all patients developed a recidive, most of them during the first year after treatment. The 5 - year survival rates of

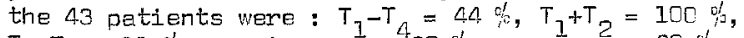
$T_{3}+T_{4}=11 \%$, carcinomas ${ }^{1}{ }^{4} 39 \%$, serodmes $=60 \%$.

Radiologische Klinik und Poliklinik der Universit: Nünster, Albert - Schweitzer - 5tr. 33, D - 4.400 Münster

\section{VHN 17}

LEVELS OF CARCINOEMBRYONIC ANTIGEN (CEA) DURING DEVELOPMENT AND THERAPY OF SQUAMOUS CELL CARCINOMAS IN THE HEAD AND NECK

M. Schröder and T. Meyer

The serum CEA levels of 134 patients with squamous cell carcinoma (scc) in the head and neck were studied at the time of diagnosis, after termination of primary therapy and every threemonths during the follow-up period. Since such patients are mostly nicotin and alcohol addicts, only CEA concentrations above $5 \mathrm{ng} / \mathrm{ml}$ were regarded as pathological values.

At the time of diagnosis $30 \%$ of the patients had clearly pathological CEA values, with a predominance of oropharyngeal and hypopharyngeal over oral cavity laryngeal carcinomas. With increasing tumor extension the incidence of pathological CEA concentrations also increased, to a greater extent in well-differentiated than in undifferentiated squamous cell carcinomas. After termination of the primary therapy we found no correlation between success of treatment and serum CEA concentration. Studies of the course of CEA values in tumor-free patients revealed both rising and falling serum values during the period of observation. It was not possible to male an early diagnosis of tumor recurrences with the aid of increasing CEA concentrations. CEA exhibits only moderate sensitivity towards squamous cell carcinomas of the head and neck. As correlations between the course of the disease and CEA concentrations in serum could only rarely be observed, the usefulness of this tumor marker for controlling the course of head and neck squamous cell carcinomas must be regarded as rather low.

Hals-Nasen-Ohren-Klinik der Universität Göttingen, Geiststr. 5/10, D-3400 Göttingen 